\title{
Modelling the influence of oil content on optical properties of seawater in the Baltic Sea
}

K. Rudź

k.rudz@wm.am.gdynia.pl

\section{Darecki}

\section{H. Toczek}

Gdynia Maritime University, Department of Physics, Gdynia, 81-225, Poland

Institute of Oceanology of Polish Academy of Sciences, Sopot, 81-712, Poland

The accuracy and correct interpretation of optical parameters of seawater depend on the complete information osn the interactions between seawater components and the light field. Among components influencing the radiative transfer, the droplets of oil can cause overor underestimation of modelled and measured optical quantities, especially in closed seas and coastal zones. Oil content in the Baltic Sea varies from several ppb in the open sea to several ppm in estuaries or ship routes. Oil droplets become additional absorbents and attenuators in seawater causing changes in apparent optical properties. These changes can potentially enable remote optical detection of oil-in-water emulsion in visible bands. To demonstrate potential possibilities of such optical remote sensing, a study of inherent optical properties of two types of crude oil emulsion was conducted, i.e. high absorptive and strongly scattering Romashkino, and low absorptive and weakly scattering Petrobaltic. First, the calculations of spectral absorption and scattering coefficients as well as scattering phase functions for oil emulsions were performed on the basis of Lorentz-Mie theory for two different oil droplets size distributions corresponding to a fresh and 14-days aged emulsions. Next, radiative transfer theory was applied to evaluate the contribution of oil emulsion to remote sensing reflectance $R_{r s}(\lambda)$. Presented system for radiative transfer simulation is based on Monte Carlo code and it involves optical tracing of virtual photons. The model was validated by comparison of $R_{r s}(\lambda)$ simulated for natural seawater to $R_{r s}(\lambda)$ from in situ measurements in Baltic Sea. The deviation did not exceed $10 \%$ for central visible wavelengths and stayed within $5 \%$ for short and long wavelengths. The light Petrobaltic crude oil in concentration of $1 \mathrm{ppm}$ causes typically a $10-30 \%$ increase of $R_{r s}$ while the heavy Romashkino reduces $R_{r s}$ for 30-50\%.

[DOI: http://dx.doi.org/10.2971/jeos.2013.13063]

Keywords: Seawater, oil-in-water emulsion, remote sensing reflectance, modelling

\section{INTRODUCTION}

Optical properties of water bodies carry important information about the composition, dynamics and processes in seawater. This information is widely used to derive ocean parameters for climate study and environmental management purposes. Currently, satellite ocean colour data are used to monitor and understand climate change on global and local scales, to forecast and observe natural phenomena of societal consequence, such as harmful algal blooms, hurricanes or sand storm), and to gather useful information for offshore and coastal zone management $[3,8]$.

Satellite ocean colour data are verified and validated by referencing in situ data. Spectral remote sensing reflectance, $R_{r s}(\lambda)$, determined from top-of-atmosphere radiance after atmospheric correction, is the primary data product used for the generation of higher level products (such as chlorophylla concentration). As a consequence, access to accurate in situ $R_{r s}(\lambda)$ is essential for the assessment of primary data products from satellite ocean colour missions $[19,20]$. To meet the growing requirements of accurate satellite measurements (approaching $2 \%$ uncertainty) it is necessary to apply local methods and models that account for all seawater constituents, such as mineral particles [18], coloured dissolved organic matter (CDOM) [6], micro-bubbles [21], or oil droplets [12].

Radiative transfer in seawater is the physical basis for quantitative ocean optics including ocean colour remote sensing. The conservation of energy in the interaction of light and water is described by the radiative transfer equation (RTE). The time-independent form of RTE for horizontally homogenous water, widely used in oceanography, is expressed by the following formula [10]:

$$
\begin{aligned}
\cos \theta & \frac{d L(z, \theta, \varphi, \lambda)}{d z}=-c(z, \lambda) L(z, \theta, \varphi, \lambda) \\
& +\int_{4 \pi} L\left(z, \theta^{\prime}, \varphi^{\prime}, \lambda\right) \beta(z, \psi, \lambda) d \Omega^{\prime}+S(z, \theta, \varphi, \lambda)
\end{aligned}
$$

where:

$\mathrm{L}(\mathrm{z}, \theta, \varphi, \lambda)$ - radiance as a function of depth $\mathrm{z}$ in the sea, zenith angle $\theta$, azimuth angle $\varphi$, and wavelength $\lambda$,

$c(z, \lambda)$ - total light beam attenuation coefficient equal to the sum of absorption coefficient and scattering coefficient: $\mathrm{c}(\mathrm{z}, \lambda)=\mathrm{a}(\mathrm{z}, \lambda)+\mathrm{b}(\mathrm{z}, \lambda)$

$\beta(\mathrm{z}, \psi, \lambda)$ - volume scattering function (describing angular 
distribution of scattering process),

$\psi$ - scattering angle between the direction of incident light $(\theta, \varphi)$ and the direction of scattered light $\left(\theta^{\prime}, \varphi^{\prime}\right)$,

$\mathrm{S}(\mathrm{z}, \theta, \varphi, \lambda)$ - source function describing emission and inelastic scattering into the beam (such as fluorescence or bioluminescence).

Oil droplets become additional absorbents and attenuators in many water regions as a consequence of increasing shipping activities and oil transportation. Their presence can considerably affect optical properties of near-surface water, especially in the the areas more exposed to pollution, like coastal zones, estuaries, marine transportation routes or oil fields $[15,16]$. The main types of oil pollution in seawater are crude oils, lubricate oils and fuel oils, flowing in with the rivers or coming from ship routine activities and discharges. While a small fraction of oil from these sources dissolves within seawater $(0.2-0.7 \%)$, most persists as dispersed droplets (oil-in-water emulsion). Oil emulsion amounts to over $80 \%$ of the total oil pollution in Baltic Sea estimated to be 76 thousand tons per year (HELCOM, 1993). According to the MARPOL convention, ship discharge waters may legally contain up to $15 \mathrm{ppm}$ of oil. In some regions the limits are more restrictive, e.g. up to $5 \mathrm{ppm}$ in Canadian inland waters.

There is a need of gathering comprehensive datasets containing all the information necessary for a complete radiative transfer calculation, which is more important in optically complex waters. Inherent optical properties (IOPs) such as absorption $a(\lambda)$, scattering $b(\lambda)$, and attenuation $c(\lambda)$ are essential inputs for radiative transfer models for computing light fields in seawater [11, 22]. However, the quantitative use of these data requires taking into account all local seawater constituents. Currently there is insufficient data and no applied methods to estimate the influence of dispersed oil on the upwelling light field of seawater [14]. The presence of oil-in-water emulsion is usually not taken into consideration.

\section{METHOD}

Numerical radiative transfer simulations are used to predict the upwelling light stream using given seawater inherent optical properties. Light propagation is computed for specified conditions and allows evaluating the influence of each factor on remote sensing reflectance separately [9]. The above mentioned inherent optical properties of oil-in-water emulsions have been implemented into a system of radiative transfer simulation based on Monte Carlo code in order to estimate their influence on remote sensing reflectance [4]. Monte Carlo methods, developed during the second world war, are now widely used for radiative transfer modelling purposes, particularly to solve the time-dependent radiative transfer equation or to address 3D problems, such as modelling the influence of sensor geometry on measured parameters, corrections for selfshadowing of sensors and measurement platforms, or analysis of light propagation in turbulent media [2]. Monte Carlo methods effectively account for multiple scattering by mathematically following many photon packets until they contain a negligible amount of energy. The Monte Carlo code involves optical tracing of photons within a given solid sector of up-

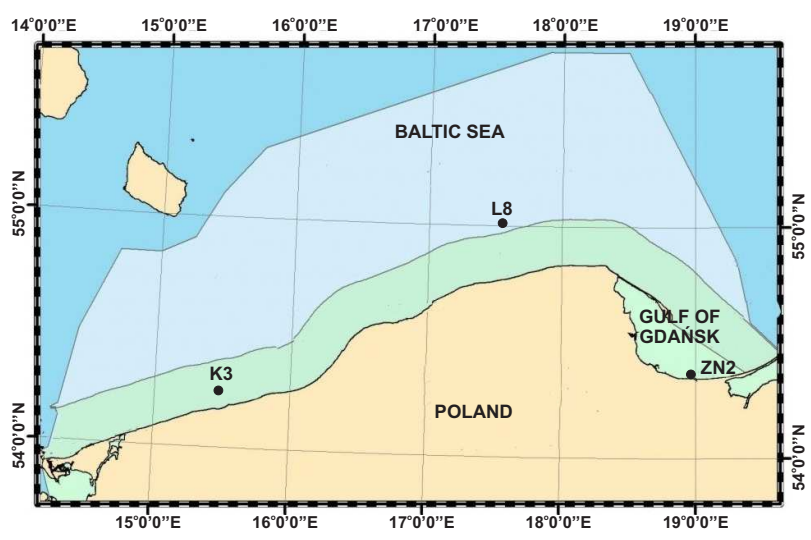

FIG. 1 The map of in situ measurement stations in the Baltic Sea.

per hemisphere, on the basis of probability of visible light absorption and scattering by seawater constituents, including oil droplets. It allows conducting single-wavelength simulations limited to the wavelengths of which the seawater IOPs are known. It does not include inelastic scattering.

Oil dispersed in seawater forms spherical droplets and bulk light scattered from droplet populations has been accurately modelled with single-scatter formulations of the RTE $[1,12]$. Lorentz-Mie theory allows computing the IOPs of oil emulsion on the basis of complex spectral refractive index of light in particles matter and particle droplets size distribution.

Radiative transfer simulations were conducted using in-situ input data from the region of Southern Baltic Sea in order to address presented method to the natural environment. Baltic Sea is a "special area" under MARPOL Convention, in which, according to the International Maritime Organization, for technical reasons relating to their oceanographical and ecological condition and to their sea traffic, the adoption of special mandatory methods for the prevention of sea pollution is required. For this study, three stations with different optical properties were chosen (Figure 1): in the Gulf of Gdansk (ZN2), in open Baltic Sea (L8), and in the estuary (K3). Measurements of light absorption and attenuation were conducted in April and May 2012 using in-situ spectrophotometer AC-9 (WET Labs Inc.) onboard R/V Oceania, owed by the Institute of Oceanology of Polish Academy of Sciences.

\subsection{Model description}

A layered seawater model formulated into Monte Carlo code was created in order to discretize continuous values of IOPs for the purpose of conducting radiative transfer simulations (Figure 2). The depth of each layer was chosen separately for every in situ station considering the depth-dependence of absorption and scattering coefficients (see Appendix). Only the surface layer (usually 0-5 m) was artificially polluted by Petrobaltic and Romashkino crude oil emulsions in two different droplet size distributions and in concentrations of 1-10 ppm.

The boundary conditions are: (i) downwelling irradiance calculated from the incident solar light zenith angle (modelling the sun height), the coefficient of sky diffusion and given number of incident photons; (ii) sea surface optical character- 
istics described by Fresnel formulas and statistical distribution of wave slopes, parameterized by the wind speed (Cox and Munk distribution) [23]; (iii) sea bottom reflectance coefficient. Simulations were conducted for the sea surface characterized by a typical wind speed of $5 \mathrm{~m} / \mathrm{s}$, clear sky conditions (70\% direct sun irradiance, 30\% diffusive sky irradiance), and a lambertian seafloor typical for the Baltic Sea sand (2\% reflected light, $8 \%$ diffused light).

The model output data is the remote sensing reflectance $R_{r s}$ calculated as the ratio of the water-leaving radiance $\mathrm{Lw}$ to the downward sky irradiance $E_{d}$ :

$$
R_{r s}=\frac{L_{w}}{E_{d}}
$$

$L_{w}$ was calculated within the half angle of $7^{\circ}$, what corresponds to the field of view of the radiometer used for validation of the results (Ramses radiometer, Trios $\mathrm{GmbH}$ ).

\subsection{Input data for radiative transfer model}

The input data for the radiative transfer simulations are the inherent optical properties of all seawater components and the boundary conditions. The optical model of water body consists of three elements:

1. Pure water - with spectral absorption coefficient given by Pope and Fry (1997) and spectral scattering coefficient given by Smith and Baker (1981).

2. Common natural components of seawater - particles and dissolved organic matter described by total spectral absorption and attenuation coefficients measured in the Baltic Sea and scattering phase functions adapted from Petzold (1972) and measured locally in the Baltic Sea $[9,7,5]$.

3. Oil droplets of two types of crude oil - with optical characteristics calculated on the basis of Lorentz-Mie theory (Figure 3). The input data used in calculations consist of the complex refractive index of light and the size distribution of oil droplets. The relative complex refractive index of light $m_{r e l}$ for oil droplets suspended in water is defined as follows:

$$
m_{r e l}=n^{\prime}-i k=\frac{n_{c}}{n_{w}}-i a \frac{\lambda_{0}}{4 \pi n_{w}}
$$

where:

$n_{c}, n_{w}$ - real refractive indexes of crude oil and seawater respectively,

a - absorption coefficient of oil,

$\lambda_{0}$ - wavelenght of light in vacuum.

The real part of the refractive index $n^{\prime}$ describes the change of the light speed after passing through the border of two media. It impacts the computed oil volume scattering function. The imaginary part $\mathrm{k}$ contains information about the absorption of light in oil. Spectral variability of both, the real and imaginary parts of complex refractive indexes of considered crude oils are presented in the Figure 3.

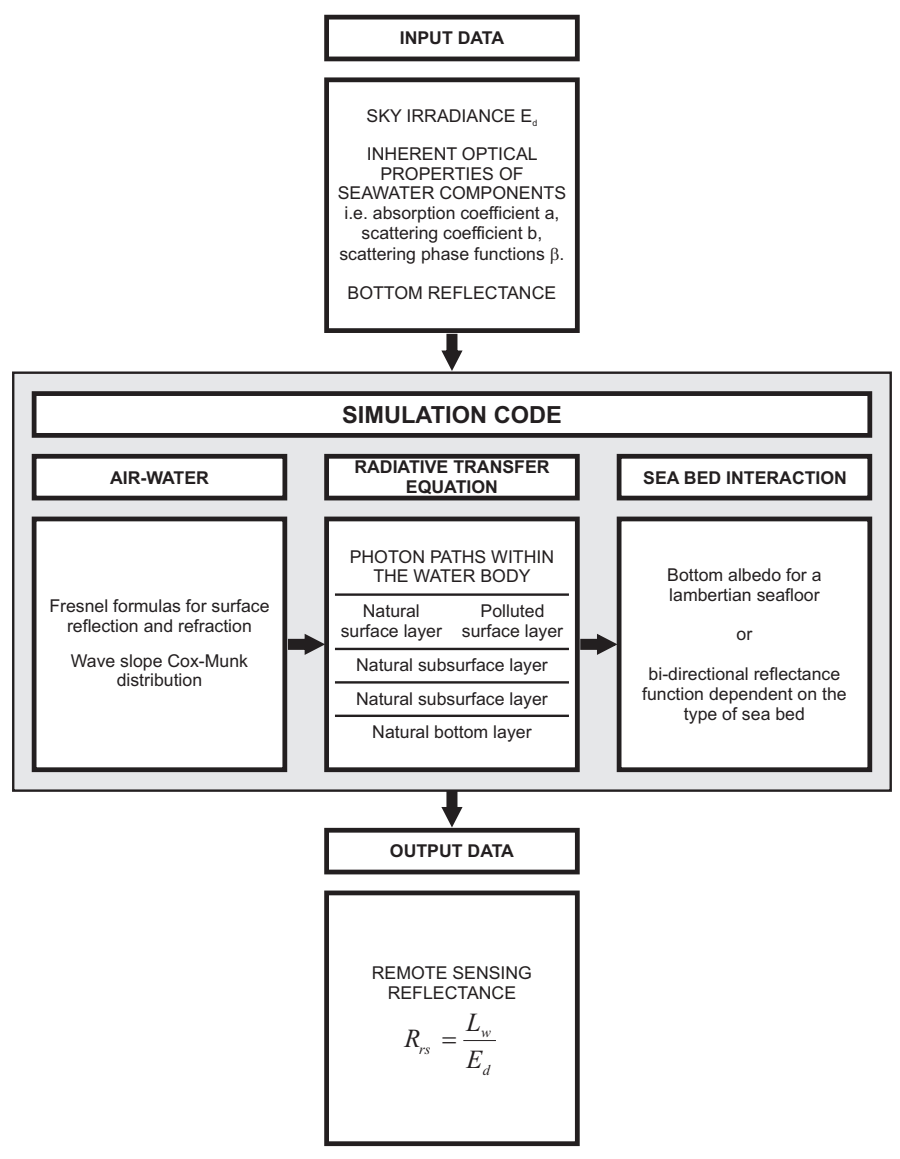

FIG. 2 General scheme of the optical model of seawater framed into Monte Carlo radiative transfer simulation code.

It was determined, that size distribution can be described by a log-normal size distribution function [17]:

$$
f(r)=A \exp \left(-\frac{\ln ^{2} \frac{r}{r_{0}}}{2 \sigma^{2}}\right)
$$

where:

A - quantity parameter,

$r_{0}$ - radius of the size distribution peak,

$\sigma$ - parameter of the shape of size distribution.

Two sets of parameters were used in the calculations: $r_{0}=0.25 \mu \mathrm{m}$ with parameter $\sigma=1.02$ (corresponding to a freshly homogenized emulsion) as well as $r_{0}=0.08 \mu \mathrm{m}$ with $\sigma=0.87$ (corresponding to the emulsion after 14 days of ageing). The results of calculations of spectral IOPs of oil-in-water emulsions are shown in the Figure 4 and Figure 5.

The influence of oil droplets on the seawater IOPs depends not only on the type and concentration of oil, but also on the degree of droplet break-up (see Figure 6). In this study we present two types of crude oil transported through the Baltic Sea characterized by different optical properties. The transparent Petrobaltic represents light crude oils and it is extracted offshore in the Southern Baltic region. The real part of it's refractive index varies spectrally from 1.47 to 1.49 in the visible bands and slightly depends on temperature [15]. The imaginary parts is highly variable $\left(10^{-5}-10^{-2}\right)$ and implies strong variability in absorption. The opaque Romashkino heavy crude oil, extracted onshore in the Volga-Ural basin in Russia, also represents the pollution from river inflows. The real part of 

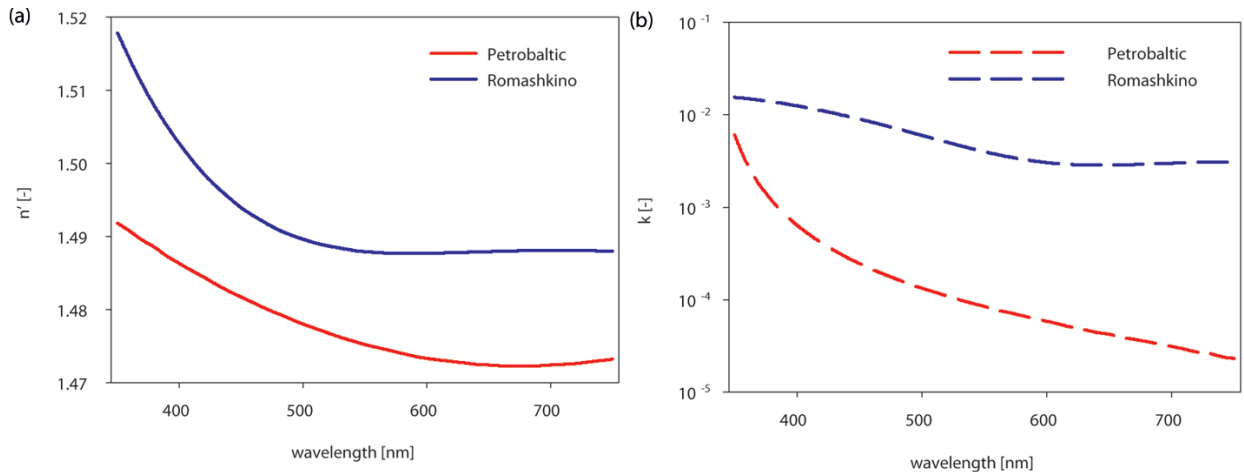

FIG. 3 The spectra of real part $n^{\prime}$ and imaginary part $\mathrm{k}$ of the complex refractive index of light of Petrobaltic and Romashkino crude oils.
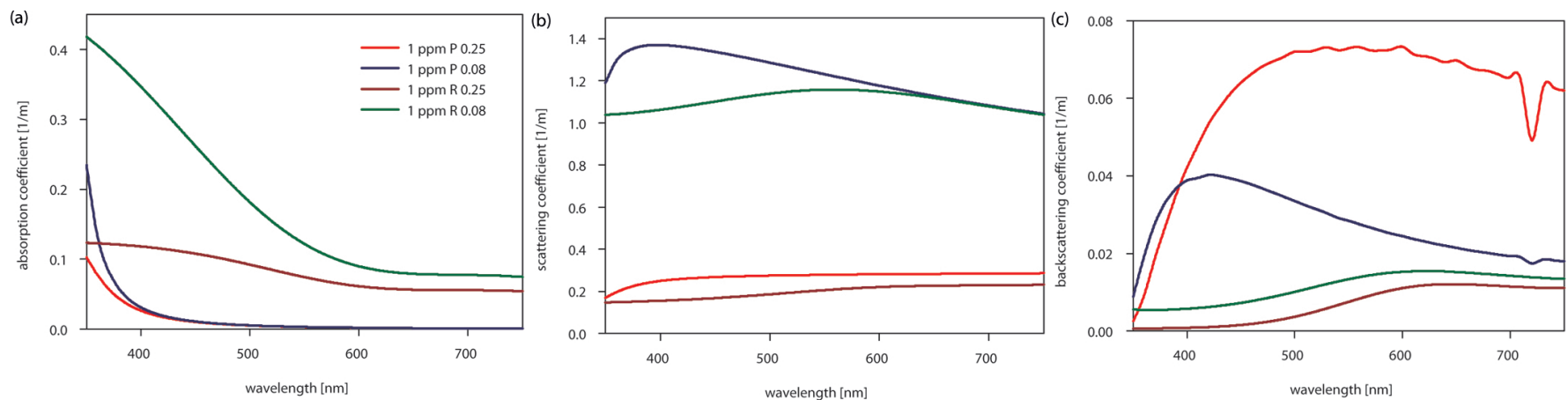

FIG. 4 Spectral absorption, total scattering and backscattering coefficients of oil-in-water emulsions Petrobaltic ( $\mathrm{P}$ ) and Romashkino ( $\mathrm{R}$ ) in concentration of 1 ppm calculated on the basis of Lorenz-Mie theory for two different droplets size distributions marked by the value of radius of the size distribution peak $r_{0}$ (in $\mu \mathrm{m}$ ).
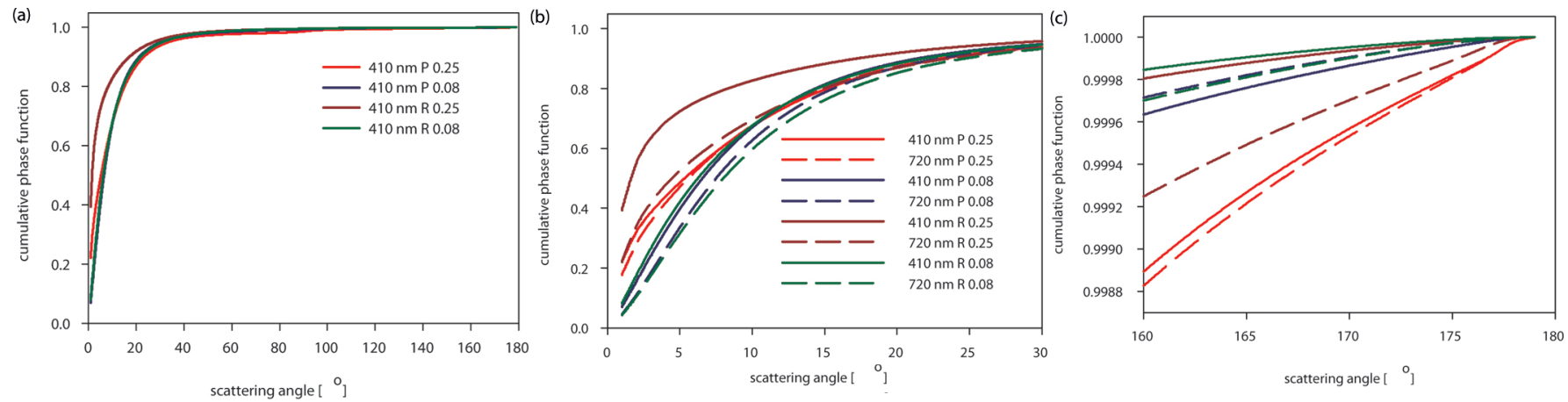

FIG. 5 Phase functions of oil-in-water emulsions in the cumulative form. Left graph shows the variability with the type of oil and droplets size distribution. Central and right graphs show the wavelength dependence for small and large scattering angles respectively.

it's refractive index is higher and varies spectrally from 1.49 to 1.52 in the visible bands. The imaginary part is less variable $\left(\sim 10^{-2}\right)$ and results in higher absorption. The study shows that Petrobaltic droplets in concentration of 1 ppm slightly increase seawater absorption (for less than $3 \%$ in the visible bands), and more significantly increase the total scattering coefficient. The impact on scattering coefficient depends on the real part of the complex refractive index (i. e. the type of oil) and size distribution of oil droplets. It varies from almost $50 \%$ for larger droplet radii $\left(r_{0}=0.25 \mu \mathrm{m}\right)$ to quadrupled values for small radii $\left(r_{0}=0.08 \mu \mathrm{m}\right)$. Romashkino droplets in the same concentration increase the total absorption coefficient from over $30 \%$ (large droplets) to about $65 \%$ (small droplets), and give respectively over $30 \%$ contribution to the scattering coefficient from large droplets and a 3-4 fold contribution from small droplets. The impact on absorption reaches maximum in the central part of the visible light, and the impact on scattering slightly increases with wavelength.

\section{RESULTS AND DISCUSSION}

Model accuracy was preliminarily evaluated by comparison of in situ $R_{r s}(\lambda)$ with simulated $R_{r s}(\lambda)$ for natural seawater. The best fit (up to $5 \%$ of percentage deviation) was achieved for the wavelengths of 410, 488 and $510 \mathrm{~nm}$. Model accuracy is strongly affected by the choice of scattering phase function (see Figure 7), whereas small modification of the boundary conditions seems to be insignificant.

Results of modelling the influence of oil content on $R_{r s}(\lambda)$ show the magnitude of impact of several factors: the type of oil product, i.e. the IOPs of oil-in-water emulsion (Figure 8), the concentration of dispersed oil (Figure 9), the size distribution of oil droplets (Figure 10) as well as the optical properties of natural components of seawater (Figure 8). Fresh Petrobaltic emulsion (larger droplets) cause in average a 30\% increase of $R_{r s}$ by the concentration of $1 \mathrm{ppm}$. The effect grows propor- 

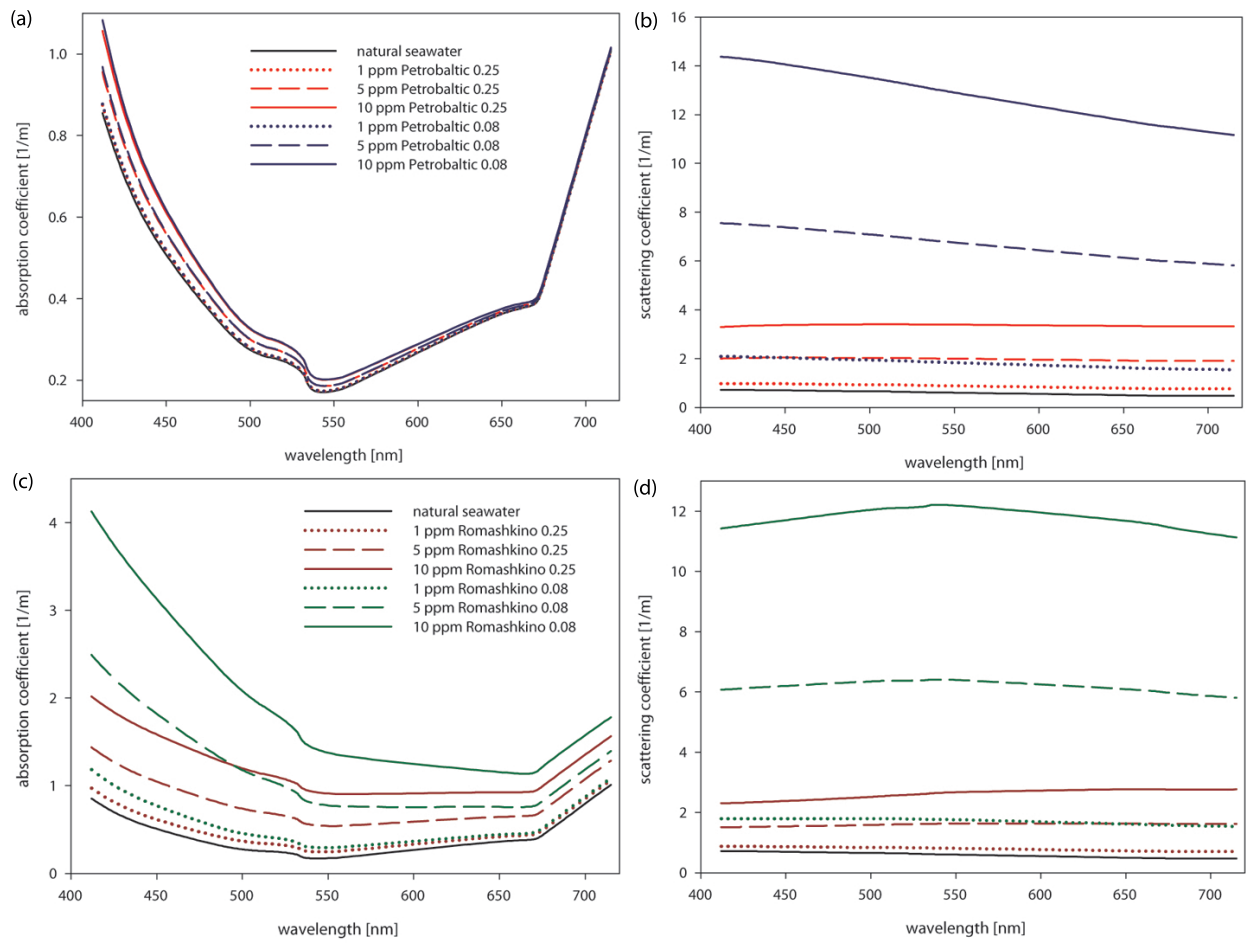

FIG. 6 Spectral absorption and scattering coefficients for the surface layer of natural seawater at the station L8 (black line) and seawater artificially polluted by Petrobaltic and Romashkino droplets (colour lines).

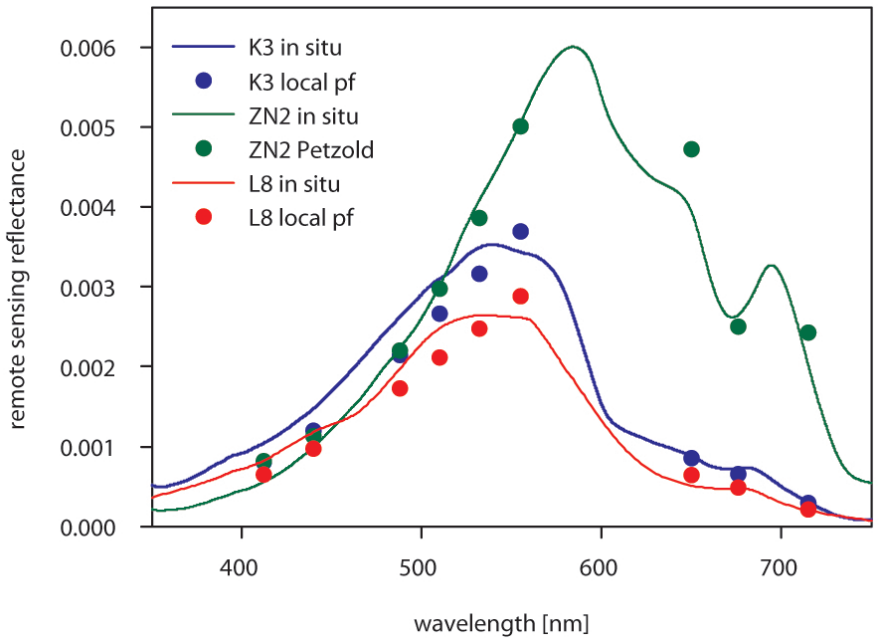

FIC. 7 Comparison between $R_{r s}(\lambda)$ measured in situ (solid lines) and modelled (dots) using different scattering phase functions.

tionally with concentration. However, the same concentration of 14 days aged emulsion (smaller droplets) gives a doubled $60 \%$ increase of $R_{r s}$ which grows more rapidly with concentration, reaching 8 -fold by 5 ppm and 20 -fold by 10 ppm. Remote sensing reflectance increases with the backscatter ratio and decreases with the increase of absorption coefficient. Therefore, in case of Petrobaltic crude oil, mainly its scattering properties influence $R_{r s}$.

The influence of Petrobaltic emulsion is more noticeable in barely absorptive seawater (e.g. station K3), while Romashkino causes more significant drop of $R_{r s}$ in weakly scattering environment (e.g. station $\mathrm{ZN} 2$ ).

In the contrary, the influence of Romashkino emulsion is more complex: we observe a reduction of $R_{r s}$ in the range of 400$600 \mathrm{~nm}(15-20 \%$ for $1 \mathrm{ppm})$ and a gain for longer waves (10$15 \%$ for $1 \mathrm{ppm})$. The effects increase slightly in both directions with oil concentration and more remarkably with the degree of droplets break-up, showing the combination of absorption and backscattering influence. The reduction of $R_{r s}$ in the short-wave part of spectrum is caused by the high absorption coefficient, but for the longer waves the contribution of backscattered light becomes dominant.

\section{CONCLUSION}

The remote sensing reflectance from seawater, which is the input of algorithms for deriving many ocean parameters from remote sensing methods (including satellite remote sensing) can be influenced by dispersed oil in the near-surface water column. Interpretation of reflectance spectra requires a simultaneous multi-parameter analysis of light propagation in seawater. The influence of most parameters on $R_{r s}(\lambda)$ is nonlinear and often superimposed by other factors. However, it can be studied separately in terms of numerical radiative transfer simulations. The contribution of different types of oil to $R_{r s}(\lambda)$ can be theoretically estimated by including optical properties of oil droplets to radiative transfer modelling. The presented study connects radiative transfer process in seawater with the inherent optical properties of dispersed oil. It creates the tools to evaluate the potential contribution of oil content to the upwelling light measured with remote sensing methods.

In general, the presence of high-absorptive and lowbackscattering oil droplets is easily observed on any marine water background, as they cause a significant decrease of $R_{r s}$. Those features usually imply opaque oils with large- 

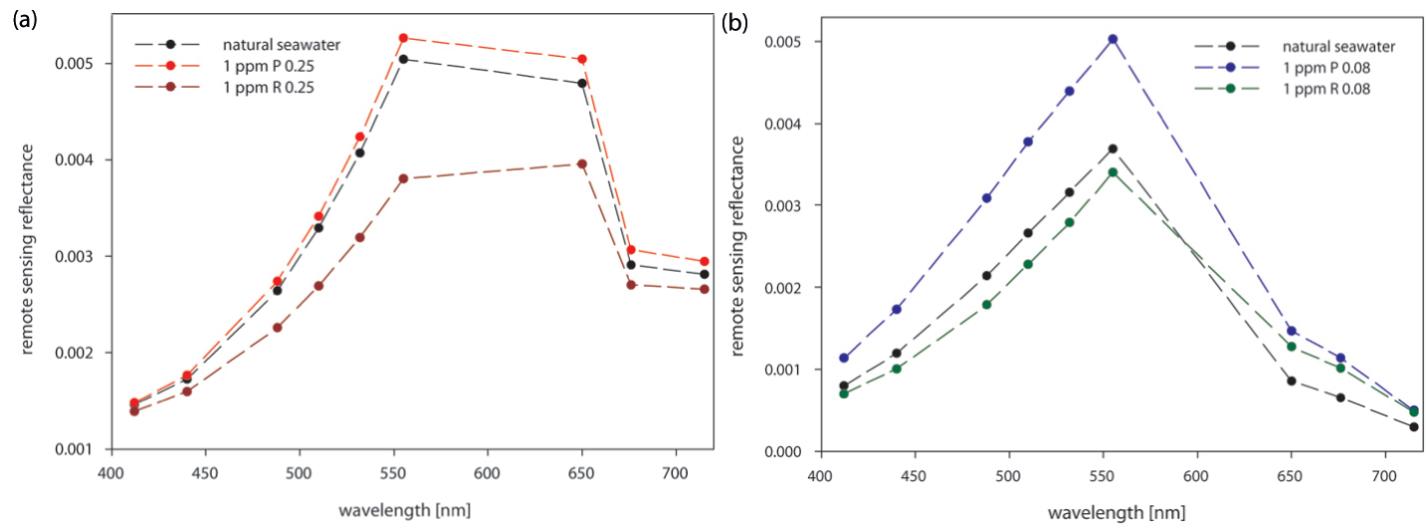

FIG. 8 Modelling the effect of the type of oil on $R_{r s}(\lambda)$. Input data for simulations are taken from stations ZN2 (left graph) and K3 (right graph).
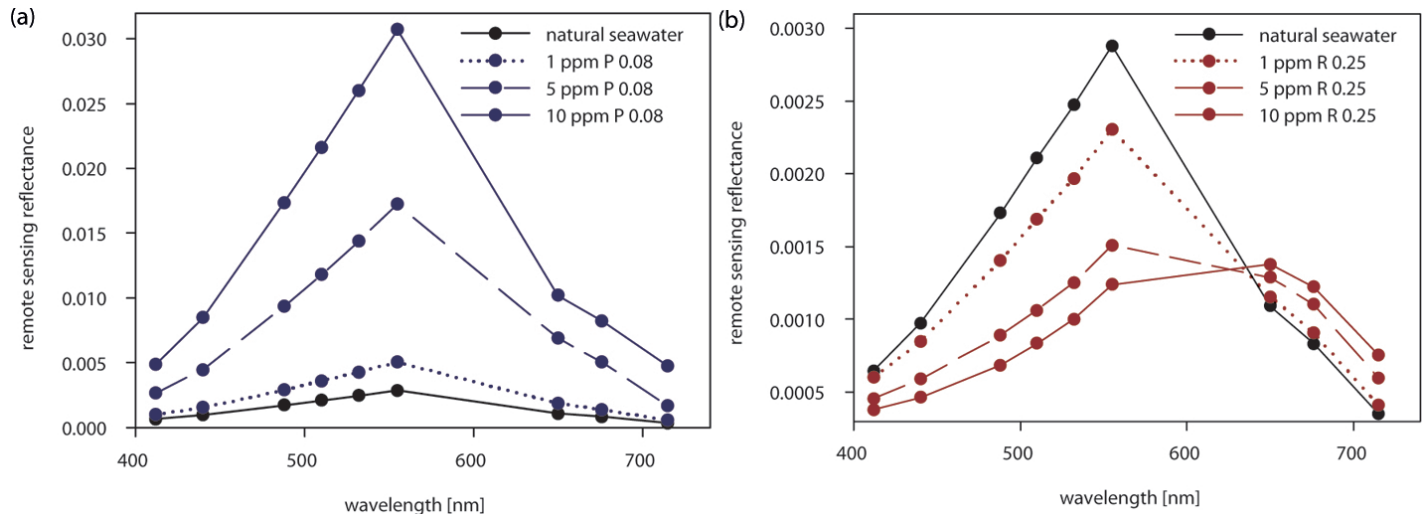

FIG. 9 The effect of the concentration of oil on $R_{r s}$. Input data for simulations are taken from station L8.
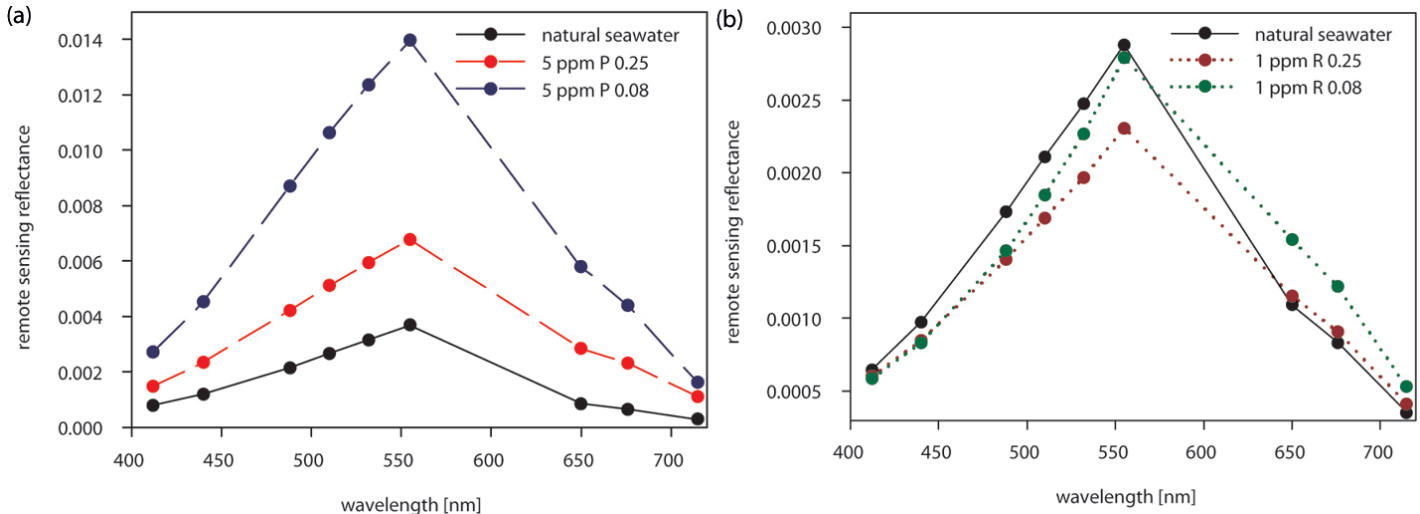

FIG. 10 The effect of the size distribution of oil droplets on $R_{r s}(\lambda)$. Input data for simulations are taken from stations $\mathrm{K}_{3}$ (left graph) and L8 (right graph).

sized droplets, which scatter light more efficiently into near-forward directions. On the other hand, high backscatter fraction (usually observed for small-sized particles) as well as low absorption coefficient (characteristic for transparent oils) increase $R_{r s}$. In case of oils with combined optical properties, e.g. high-absorptive and high-backscattering, the impact on $R_{r s}$ becomes more complex and more concentrationdependent, but is still possible to evaluate.

Quantitative radiative transfer computations can contribute to the improvement of satellite algorithms accuracy for the determination of parameters derived from the water-leaving radiance, regarding coastal zones, estuaries, main marine transportation routes and oil extraction areas. It can also improve the accuracy of shipboard and offshore $R_{r s}$ measurements, which are used for the purpose of calibration of satellite data and for seawater monitoring. It is also possible that it will enable the remote detection of oil-in-water emulsion. As a next step, environmental measurements of the natural sea water polluted by oil emulsion will be performed in order to confirm modelled results.

\section{ACKNOWLEDGEMENTS}

This paper was supported by Gdynia Maritime University statutory researches No. 360/DS/2013 and SatBałtyk project funded by the European Union through European Regional Development Fund, (contract No. POIG.01.01.02-22-011/09 entitled „The Satellite Monitoring of the Baltic Sea Environ- 
ment"). Authors would like to thank Jacek Piskozub for the access and practical introduction to the Monte Carlo code, Sławomir Sagan for making the Baltic Sea IOPs data available, and Włodzimierz Freda for conducting calculations of oil emulsion IOPs. Special thanks are handed to Oliver Zielinski for practical advice in the matters of marine sensors and data interpretation.

\section{APPENDIX}

\begin{tabular}{|c|c|c|c|c|c|c|c|c|}
\hline \multirow{3}{*}{$\begin{array}{l}\text { wave } \\
\text { length }\end{array}$} & \multicolumn{4}{|c|}{ ABSORPTION COEFFICIENT } & \multicolumn{4}{|c|}{ SCATTERING COEFFICIENT } \\
\hline & \multicolumn{8}{|c|}{ Station K3 } \\
\hline & Ilayer & II layer & III layer & IV layer & I layer & II layer & III layer & IV layer \\
\hline$[\mathrm{nm}]$ & $0-2 \mathrm{~m}$ & $2-4 \mathrm{~m}$ & $4-7 \mathrm{~m}$ & $7-10 \mathrm{~m}$ & $0-2 \mathrm{~m}$ & $2-4 \mathrm{~m}$ & $4-7 \mathrm{~m}$ & $7-10 \mathrm{~m}$ \\
\hline 412 & 0.8847 & 0.8490 & 0.7593 & 0.6900 & 0.9180 & 0.7985 & 0.5543 & 0.2913 \\
\hline 440 & 0.5883 & 0.5625 & 0.4893 & 0.4290 & 0.8967 & 0.7785 & 0.5487 & 0.2897 \\
\hline 488 & 0.3153 & 0.2995 & 0.2540 & 0.2137 & 0.8550 & 0.7440 & 0.5390 & 0.2857 \\
\hline 510 & 0.2317 & 0.2210 & 0.1883 & 0.1580 & 0.8410 & 0.7400 & 0.5410 & 0.2877 \\
\hline 532 & 0.1740 & 0.1655 & 0.1403 & 0.1190 & 0.8107 & 0.7140 & 0.5267 & 0.2810 \\
\hline 555 & 0.1237 & 0.1170 & 0.0977 & 0.0817 & 0.7783 & 0.6870 & 0.5120 & 0.2760 \\
\hline 650 & 0.0357 & 0.0330 & 0.0243 & 0.0177 & 0.6653 & 0.5875 & 0.4577 & 0.2560 \\
\hline 676 & 0.0377 & 0.0335 & 0.0240 & 0.0123 & 0.6373 & 0.5635 & 0.4407 & 0.2470 \\
\hline \multirow[t]{2}{*}{715} & 0.0000 & 0.0000 & 0.0000 & 0.0000 & 0.6340 & 0.5615 & 0.4467 & 0.2543 \\
\hline & \multicolumn{8}{|c|}{ Station L8 } \\
\hline & I layer & II layer & III layer & IV layer & I layer & II layer & III layer & IV layer \\
\hline$[\mathrm{nm}]$ & $0-5 \mathrm{~m}$ & 5-12 m & $12-16 \mathrm{~m}$ & $16-24 \mathrm{~m}$ & $0-5 \mathrm{~m}$ & 5-12 m & $12-16 \mathrm{~m}$ & $16-24 \mathrm{~m}$ \\
\hline 412 & 0.8373 & 0.8390 & 0.7198 & 0.6230 & 0.7145 & 0.7171 & 0.4408 & 0.2301 \\
\hline 440 & 0.5578 & 0.5600 & 0.4653 & 0.3843 & 0.6992 & 0.7026 & 0.4360 & 0.2319 \\
\hline 488 & 0.2983 & 0.2987 & 0.2400 & 0.1883 & 0.6580 & 0.6633 & 0.4245 & 0.2301 \\
\hline 510 & 0.2202 & 0.2197 & 0.1765 & 0.1388 & 0.6462 & 0.6511 & 0.4230 & 0.2328 \\
\hline 532 & 0.1642 & 0.1630 & 0.1325 & 0.1048 & 0.6187 & 0.6237 & 0.4078 & 0.2278 \\
\hline 555 & 0.1135 & 0.1126 & 0.0910 & 0.0715 & 0.5930 & 0.5987 & 0.3963 & 0.2270 \\
\hline 650 & 0.0305 & 0.0304 & 0.0220 & 0.0154 & 0.4967 & 0.5051 & 0.3508 & 0.2135 \\
\hline 676 & 0.0282 & 0.0290 & 0.0213 & 0.0105 & 0.4762 & 0.4843 & 0.3378 & 0.2050 \\
\hline \multirow[t]{2}{*}{715} & 0.0000 & 0.0000 & 0.0000 & 0.0000 & 0.4683 & 0.4773 & 0.3433 & 0.2134 \\
\hline & \multicolumn{8}{|c|}{ Station ZN2 } \\
\hline & Ilayer & II layer & III layer & & I layer & II layer & III layer & \\
\hline$[\mathrm{nm}]$ & $0-4 \mathrm{~m}$ & $4-11 \mathrm{~m}$ & $11-22$ & & $0-4 \mathrm{~m}$ & $4-11 \mathrm{~m}$ & $11-22$ & \\
\hline 412 & 2.556 & 1.139 & 1.726 & & 3.539 & 1.445 & 8.219 & \\
\hline 440 & 1.836 & 0.744 & 1.175 & & 3.431 & 1.388 & 8.116 & \\
\hline 488 & 1.025 & 0.383 & 0.645 & & 3.529 & 1.362 & 7.816 & \\
\hline 510 & 0.783 & 0.278 & 0.480 & & 3.594 & 1.368 & 7.673 & \\
\hline 532 & 0.604 & 0.210 & 0.356 & & 3.614 & 1.334 & 7.504 & \\
\hline 555 & 0.461 & 0.149 & 0.246 & & 3.634 & 1.320 & 7.321 & \\
\hline 650 & 0.213 & 0.064 & 0.099 & & 3.575 & 1.211 & 6.546 & \\
\hline 676 & 0.446 & 0.109 & 0.156 & & 3.312 & 1.187 & 6.342 & \\
\hline 715 & 0.000 & 0.000 & 0.000 & & 3.707 & 1.225 & 6.193 & \\
\hline
\end{tabular}

TABLE 1 Table of the in situ data collected at the field stations: $\mathrm{K}_{3}, \mathrm{~L}_{8}$ and $\mathrm{ZN}_{2}$ using AC9 Wetlabs spectrophotometer (calibrated to pure water).

\section{References}

[1] T. Król, A. Stelmaszewski, and W. Freda, "Variability In the optical properties of a crude oil - seawater emulsion," Oceanologia 48(S), 203-211 (2006).

[2] D. J. Bogucki, J. Piskozub, M.-E. Carr, and G. D. Spiers, “Monte Carlo simulation of propagation of a short light beam through turbulent oceanic flow," Opt. Express 15(21), 13988-13996 (2007).

[3] M. Darecki, and D. Stramski, "An Evaluation of Modis And Seawifs Bio-Optical Algorithms In The Baltic Sea," Remote Sens. Environ. 89, 326-350 (2004).

[4] W. Freda, and J. Piskozub, "Revisiting the role of oceanic phase function in remote sensing reflectance," Oceanologia 54(1), 29-38 (2012).

[5] W. Freda, T. Król, and 0. V. Martynov, "Measurements of scattering function of sea water in southern Baltic," Eur. Phys. J-Spec. Top. 144, 147-154 (2007).

[6] P. Kowalczuk, C. A. Stedmon, and S. Markager, "Modeling absorption by CDOM in the Baltic Sea from season, salinity and chlorophyll," Mar. Chem. 101(1), 1-11 (2006).
[7] I. Levin, M. Darecki, S. Sagan, and T. Radomyslskaya, "Relationships between inherent optical properties in the Baltic Sea for application to the underwater imaging problem," Oceanologia 55(1), 11-26 (2013).

[8] E. Lysiak-Pastuszak, M. Bartoszewicz, K. Bradtke, M. Darecki, N. Drgas, Kowalczuk, W. Kraśniewski, et al., "A study of episodic events in the Baltic Sea - combined in situ and satellite observations," Oceanologia 54(2), 121-141 (2012).

[9] R. A. Leathers, T. V. Downes, C. O. Davis, and C. D. Mobley, Monte Carlo Radiative Transfer. Simulations for Ocean Optics: A Practical Guide (NTiS ADA426624, 2004).

[10] C. D. Mobley, 1994., Light and Water: Radiative Transfer in Natural Waters (Academic Press, Waltham, 1994).

[11] C. D. Mobley, L. K. Sundman, and E. Boss, "Phase Function Effects On Oceanic Light Fields," Appl. Opt. 41, 1035-1050 (2002).

[12] Z. Otremba, "Oil Droplets As Light Absorbents In Seawater," Opt. Express 15(14), 8592-8597 (2007).

[13] Z. Otremba, J. Piskozub, "Phase functions of oil-in-water emulsions," Opt. Appl. XXXIV(1), 93-99 (2004).

[14] K. Rudź, E. Baszanowska, Rohde, and 0. Zielinski, "Fluorescence Methods and Monte Carlo Radiative Transfer Simulation Applied to Oil Detection in Baltic Sea," Joint Proceedings 24, 52-59 (2011).

[15] K. Rudź, 2011., "Emulsified Fuels of Machine Origin in Seawater a Contribute to Remote Detection," Journal of KONES Powertrain and Transport 18(3), 375-381 (2011).

[16] K. Rudź, M. Darecki, and H. Toczek, "Modelling of seawater polluted by light and heavy crude oil droplets," Journal of KONES Powertrain and Transport 19(2), 473-480 (2012).

[17] A. Stelmaszewski, T. Król, and H. Toczek, "Light scattering in Baltic crude oil - seawater emulsion," Oceanologia 51(3), 405-414 (2009).

[18] S. B. Woźniak, and D. Stramski, “Modeling The Optical Properties of Mineral Particles Suspended In Seawater And Their Influence On Ocean Reflectance And Chlorophyll Estimation From Remote Sensing Algorithms," Appl. Opt. 43(17), 3489-3503 (2004).

[19] B. Woźniak, K. Bradtke, M. Darecki, J. Dera, J. Dudzinska-Nowak, L. Dzierzbicka-Glowacka, D. Ficek, et al., "SatBaltyk - A Baltic environmental satellite remote sensing system - an ongoing project in Poland. Part 1: Assumptions, scope and operating range," Oceanologia 53(4), 897-924 (2011).

[20] B. Woźniak, K. Bradtke, M. Darecki, J. Dera, J. Dudzinska-Nowak, L. Dzierzbicka-Clowacka, D. Ficek, et al., "SatBaltyk - A Baltic environmental satellite remote sensing system - an ongoing project in Poland. Part 2: Practical applicability and preliminary results," Oceanologia 53(4), 925-958 (2011).

[21] 0. Zielinski, B. Saworski, and J. Schulz, "Marine bubble detection using optical-flow techniques," J. Europ. Opt. Soc. Rap. Public. 5, 1-5 (2010).

[22] M. Hieronymi, A. Macke, and 0. Zielinski, "Modeling of waveinduced irradiance variability in the upper ocean mixed layer," Ocean Sci. 8(2), 103-120 (2012).

[23] C. Cox, and W. H. Munk, "Statistics of the sea surface derived from sun glitter," J. Mar. Res. 13, 198-227 (1954). 